thought. In many cases the English text has been retranslated orally into Hebrew. A thousand students in a single year have been engaged in this study, and the Semitic languages are now subjects of study in this country to an extent unknown before.

The modern languages are far from full recognition in the courses of study in the greater number of colleges. The demand for their study as part of a liberal education is not emphasized by their position and the amount of time devoted to them. They are tolerated rather than regarded as essential. Out of sixty-four representative colleges, fifty-eight require neither French nor German for admission to the course in arts, four require French, and two either French or German. The colleges are thus reduced to the necessity of giving elementary instruction in the modern languages ; and the college does not to this extent imply advanced instruction, but simply the teaching of the rudiments. A knowledge of French and German is necessary for the highest scientific as well as classical study. The use of French and German works, the consultation of authorities found only in these languages, is impossible if their study is postponed until late in the academic course. The colleges do not reap the fruits of a knowledge of the modern languages in their subsequent instruction. The philological study of Latin embraces law Latin and the forms that have survived in French and the other Romance languages. A critical knowledge of early English is not possible without a study of the French element in English derived from the Latin. Thus the advanced study of the classics, as well as our heritage of the English tongue, is dependent upon an acquaintance with French. The study of Anglo-Saxon is promoted by a preliminary knowledge of German. Our colleges are thus fettered in their work by the lack of the elementary knowledge on the part of pupils essential to its successful prosecution. An intelligent acquaintance with modern European literature is not possible when the time which should be devoted to it is occupied with elementary study. The time which is devoted to the modern languages forms in most institutions but a small part of the regular college course, necessitating imperfect and hasty study. In sixtyfour colleges conferring the degree of bachelor of arts, the amount of time required to be spent in the study of French and German is seven and three-tenths per cent of the entire four years' course. It is required that less than four per cent of the entire time of the student shall be devoted to one of these languages. It is not to be assumed that this low amount adequately represents the entire time devoted to the modern languages, for through electives in the best colleges the study can be greatly extended; but it represents the current estimate of college faculties of the value of these studies, and the amount required to enable the student to prosecute his later work. During the same period, at least twenty-five per cent of the student's time is consumed, by compulsion, in classical study, in addition to the preliminary knowledge required before entering college. The revised curriculum which has been adopted at Yale, and other colleges where the strict classical requirement has not been retained in full force, is very encouraging. Several Western and Southern institutions, as the Universities of Michigan, Indiana, and Virginia, exhibit a thorough and extended course in the modern languages. The scientific and technical schools recognize the indispensable character of a knowledge of French and German for purposes of all advanced investigation in science and engineering. The most recent discoveries in these and allied branches are published in monographs and reviews, and it is safe to say that the highest expert testimony on a question of engineering cannot be secured except from one familiar with the constantly increasing results of foreign investigation. Such results are not immediately attainable except in the language itself; and the final word which has been uttered in discovery is often of priceless value in all industrial enterprises. There is a loss in the equipment of every scientist or engineer who cannot at once obtain from original sources the knowledge which he needs. There is an additional reason why the instruction in modern languages in our scientific courses should be increased rather than diminished. The requirements for admission to these courses are less than to the classical. An exclusively professional or technical course, unless conceived in a broad spirit, fails to give a view of the connection and relation of the physical sciences. No branch of study stands alone, and can be built up from itself. Geology embraces paleontology, and paleon- tology demands a knowledge of animal and plant forms, hence of zoölogy and botany. Chemistry touches, on the one hand, organic forms, and, on the other, inorganic, and involves the laws of physics. The highest results in every field of learning demand the highest preparation for them, and the student going out into life will find a sphere corresponding with his highest fitness. It is a misfortune to educate men out of sympathy with other fields of knowledge. The scholar whose work will be confined to a single branch needs the broadest attainable culture, which would be impossible for him later. Knowledge loses half its value when it cannot be communicated clearly, forcibly, and persuasively. Thus the student with an exclusively practical life before him cannot dispense, even for success in his own department, with the culture which springs from a linguistic training. The scholar with a clear insight into the meaning of words, and the power to marshal his thoughts effectively, can make his knowledge useful to himself and the world. Any course, whether technical or scientific, which sends out graduates without that literary training which will give a commanding weight to their views in any community, is to that extent defective, and fails to prepare them for the widest usefulness. Minor defects in subordinate, technical matters can be more readily repaired by experience than a lack of linguistic training, which will give clearness and definiteness to their thinking, and make the publication of the results of their experience a contribution to the world's knowledge.

The experiment by which in certain courses the modern languages are substituted for the classical, is one of extended application in the colleges of this country. In many institutions the students in courses in philosophy and literature are more numerous than the classical students.

We conclude that the elementary study of French and German should be begun in the public schools; that there are years in youth in which languages are acquired with unusual facility, which should be improved in any system of education.

This would enable the instruction in the modern languages in colleges to be advanced in character, so that by their use the full value of a literary, scientific, or historical course could be realized.

By requiring French or German for admission to technical courses, the benefits of a thorough knowledge of these languages would be attained without crowding the strictly professional studies, and some literary study should accompany the whole four years' course in such schools.

W. T. HEWETT.

\section{BRITISH UNIVERSITIES AND THE TRAINING OF TEACHERS.}

THERE is no professorship of education at any university of England, Wales, or Ireland. At the universities of Cambridge and London there are special examinations for teachers, on the results of which certificates or diplomas are granted; but there are no educational degrees. Technically speaking, therefore, education is not a university subject in these countries. At Cambridge, under the auspices of a teachers' training syndicate appointed by the university early in 1879 , lectures on teaching have been given for eight years past ; but they are not permanently established, and may come to an end at any time. They are, as a rule, fitfully and poorly attended, and cannot as yet be pronounced a decided success. Except in the training-colleges and at the College of Preceptors, there is no other systematic course of lectures for teachers outside Scotland. In Scotland there are two chairs of education, established in 1876 out of funds left by the well-known Dr. Bell, one at Edinburgh, and the other at St. Andrew's. Both these chairs are very ill endowed. In I 886 a school-masters' diploma was established at the University of Edinburgh.

I shall not attempt to criticise this state of things, - looked at from any point of view, it is far indeed from satisfactory, - but I shall endeavor in the space at my disposal to describe what is actually being done for the training of teachers by these various agencies.

I will begin with Cambridge, and first as to its courses of lectures. They usually consist of one set on psychology in its bearing on teaching, delivered as a rule by Mr. James Ward of Trinity College ; another set on the history of education; and a series of dis- 
connected lectures on practice delivered by prominent head masters and other teachers. Amongst these last may be mentioned as specially valuable the lectures on stimulus and on discipline, by Mr. Arthur Sidgwick, formerly an assistant master at Rugby; and one on 'A Day in a Class-Room,' by Dr. Abbott, head master of the City of London School. As far as I know, only one connected course of lectures on the practice of education has ever been delivered before the university; viz., that by Mr. Fitch, which has since appeared as his well-known ' Lectures on Teaching.' It may well be doubted whether the sporadic lectures by eminent schoolmasters above referred to can be properly said to form a part of training in any real sense; but they are certainly more attractive than a prolonged course, and are in many ways suggestive and stimulative. The reasons why these lectures as a whole are not more satisfactorily attended are mainly two, - first, because undergraduates, while reading for their degrees, have very little time to devote to other subjects; and, second, because it is the habit at our universities to look upon lectures as merely preparation for examinations, and to value examinations solely by the prizes attached to them. Now, there are no prizes attached to the teachers' examinations, and the head masters of our public schools practically ignore them altogether, while the University Agency for the supply of masters does not even mention the certificates on its form of qualifications. It is no wonder, therefore, that undergraduates do not crowd the lecture-room. It is only fair, however, to state that the lectures on education suffer no more than others under similar drawbacks. The writer of this paper, when lecturing at Cambridge a short while ago, on the history of education, can remember on one occasion to have counted as many as seventeen undergraduates present. At the time there were about nineteen hundred undergraduates at the university, of whom perhaps one-quarter were destined to become school-masters, at least for a time.

Before a candidate can enter for the examination of the Cambridge Teachers' Training Syndicate, he or she must have given evidence of something of the nature of a sound general education. The test is not, as at London and Edinburgh, that the candidate must be a graduate of the university. Some nine fairly simple examinations are named, one of which must have been passed; or, to make the condition still more elastic, the candidate must have " been presented for examination by a training-college approved by the syndicate." This lowering of the initial test, no doubt, still further removes education from the status of a university subject; but it renders the examination far more widely available, especially for women, who form about nine-tenths of the candidates as a rule. In the examination of June, I886, held at the three centres, Cambridge, London, and Cheltenham, fifty-one candidates passed, of whom only three were men (students of the Finsbury TrainingCollege). There are two certificates granted, - one for the theory, history, and practice of teaching; and, where this has been won, another may be obtained for practical efficiency in teaching. The subjects for the former are:-(I) The theory of education: $(\alpha)$ the scientific basis of the art of education, or pure psychology; (b) the elements of the art of education, or the application of psychology to school-work in the training of the faculties (the senses, memory, conception, etc). (2) The history of education in Europe since the revival of learning, a general knowledge being required of systems of education which have actually existed, of the work of eminent teachers, and of the theories of leading writers on education up to the present time. A more detailed knowledge is required of special subjects set from year to year. For example, the special subjects for I 887 are, 'John Amos Comenius, his Life and Educational Works,' by Professor Laurie, and 'The Life and Work of Arnold ;' those for 1888 will be 'Locke's Thoughts concerning Education,' and 'The Teaching of the Jansenists at Port Royal.' (3) The practice of education: $(a)$ method, which deals with actual teaching and examination; $(b)$ school management, which deals with hygiene, furniture, apparatus, time-tables, etc. One paper is set on each of three groups of subjects; and a fourth paper is added, containing a small number of questions of an advanced character on each of the three groups. It is into this paper that questions on physiology and physical training are usually introduced; but, notwithstanding this, I cannot but think that these last-named subjects are not sufficiently represented. Candidates must be twenty years old before entering for the examination, and must pay a fee of fifty shillings to the syndicate.

The certificate for practical efficiency, as I have pointed out, can only be obtained by those who already hold the certificate which I have just described. Candidates must "have been engaged in school-work for a year in some school or schools recognized for the purpose by the syndicate." Training-colleges of course come under this designation, " if the syndicate is satisfied with the duration and character of the training in practical work received by the candidates." The bases for the certificate are, $(\alpha)$ examination of the class taught by the candidate; $(b)$ an inspection of the class while being taught; $(c)$ questions put to the teacher in private after the inspection; and $(d)$ a report made by the head master or mistress. I do not think there have been many candidates for this certificate other than the students of those few training-colleges which are established for teachers of middle and higher schools. But then they are almost the only people who use the examination at all.

It may be as well to mention here that the syndicate does not prescribe the use of any particular books for its examination, except those mentioned under the head of 'special subjects.' Mr. Ward has, however, from time to time put forth a list of some of those bóoks which may be safely recommended to students, and from which they can make their own choice. I need scarcely say that Dr. Barnard's admirable compilations play a prominent part in this list.

I have given a very full description of the Cambridge scheme, both because I consider it, on the whole. the best unconnected with a training-college in Great Britain, and because by so doing I shall be saved the trouble of entering into such minute detail again. Let me mention here, for the information of the curious in such matters, that in the charter of Cavendish College, founded at Cambridge in 1876 , the objects mentioned are, "(I) To enable students somewhat younger than ordinary undergraduates to pass through a university course, and obtain a university degree; (2) To train in the art of teaching those students who intend to become schoolmasters; (3) To secure the greatest possible economy in cost as well as time." I cannot ascertain that any steps have ever been taken to realize the second object. Probably all that was meant was that the college was intended to provide 'pupil-teachers' in the elementary schools, with an opportunity for finishing their general education. Who knows but that some day we may get it to mean both that and something more?

The University of London is simply a corporation for examination purposes. It provides no lectures of any kind ; that is, it does not educate, but only tests education. . It is hoped by many that before very long this state of things may be changed; but for the present the fact stands as I have stated it. For the present, therefore, the only part the University of London can play in the higher training of teachers is that of an examiner. As I have already said, it possesses an ' examination in the art, theory, and history of teaching.' Unlike the University of Cambridge, it restricts its examination to its own graduates, and it grants a 'teacher's diploma' on the result. There is no restriction as to age, and the fee is five pounds. Four papers are set, - one on 'mental and moral science in their relation to the work of teaching;' two on ' methods of teaching and school management;' and one on 'the history of education.' The science and the methods are very much the same as at Cambridge; but the history consists solely of set books. It is described as "the lives and work of eminent teachers, and the systems of instruction adopted in foreign countries." The set books for 1887 are as follows: "History of the University of Cambridge from the Earliest Times to I 535 A.D.' by Bass Mullinger; 'Education and School,' 'Theory and Practice of Teaching,' by E. Thring ; ' On the Action of Examinations,' by Latham; 'Quelques mots sur l'Instruction publique en France,' by Michel Bréal.

There are no doubt great advantages in the direction of definiteness and thoroughness to be derived from the use of set books; but, on the other hand, it leads to this unsatisfactory position, - that in 1887 teachers will gain their diploma without having shown any particular knowledge of the public instruction of England, Germany, and Switzerland, and, what is worse, without having shown any particular knowledge of the theories and methods of Froebel and Pestalozzi. As a matter of fact, one or two questions on these last 
are generally introduced into the other papers. It may be well to note that among the many things coming under the head of methods of teaching and school management we find mentioned physical exercises, drill, and recreation. But there is another point of still greater importance. The University of London grants but one certificate, - not two, as does Cambridge, - and includes in that one, as a sine qua non, practical skill in teaching and in the management of a class. No directions are given as to how this last and most difficult test is to be applied. But hitherto the plan adopted has been to require the candidates to send in sketches of lessons on four different subjects chosen by themselves, and to give one or two of these lessons to a class in the presence of the examiners. But inasmuch as, in the necessity of things, such classes as can be got near at hand have to be chosen, the teachers know nothing personally of the children, and are quite in the dark as to the actual knowledge which the class possesses. The consequence is, that the test is far from satisfactory, and merely serves to show what a teacher will do under very distressing circumstances. At the best, it can only reveal whether a teacher is altogether incompetent : all the higher qualities must remain unassessed. A large part of those who take degrees at the University of London are the teachers of elementary and middle schools; and these, by the time they have graduated, have already had many years of school experience : hence the insistence on the practical test as an integral part of the London examination for teachers. The Cambridge examination is rather designed for those who intend to become schoolmasters and school-mistresses. The London examination has only been in existence some three or four years, and so far has been but very little made use of.

As I said at the commencement, there are two chairs of pedagogy in Scotland, - - one at the University of Edinburgh, and the other at the University of St. Andrew's. Their work is sufficiently alike to allow one description to do for both. I will choose the chair of Edinburgh, held by Prof. S. S. Laurie. ${ }^{1}$ This chair was founded in I 876 , and commenced work with fourteen students, - a number which has steadily been added to, until the total has now reached fifty-one. Of these students, about three-fifths are 'senior students' of the denominational training-colleges, who, having passed a qualifying examination in Latin and mathematics, and stood in the first division of the government list of successful candidates for Queen's scholarships (i.e., entrance scholarships at the training-colleges), are allowed to attend the university. The remainder are students who have graduated or are about to graduate. This latter class will not be likely to attend in larger numbers until either the subject of education is included in the studies qualifying for an M.A. degree, or an act is passed requiring all school-masters in Scotland above the elementary grade to hold a diploma in education. A long course of eighty-five lectures is delivered between the first of November and the first of April. Of these lectures, about a dozen are purely psychological, dealing with the intelligence and moral nature; fifty are on method, dealing with principles of teaching and the detailed application of these; the rest are on the history of education. These last naturally vary considerably from year to year; but every year a careful analysis of Quintilian and Locke is given. I must confess that the choice of these two last as staple subjects seems to me peculiar. All the students attend three examinations, and write three essays. These form the subject of professorial criticism. Those students who have not been, or who are not, training-college students practise the art of teaching in the normal schools (by permission), and are examined by the head masters of those schools on practical matters of school management. The head masters report to the professor. Last year the university instituted a school-masters' diploma specially for secondary school-masters, which, however, is to be conferred only on graduates in arts of Edinburgh. Candidates, moreover, must have attended the class of the theory, art, and history of education in the university, and must pass an examination in these subjects conducted by the professor and an examiner appointed by the university court. The subjects of examination in April, 1887, were, $(a)$ the professor's lectures; $(b)$ Locke, 'On the Conduct of the Human Understanding;' (c) Milton, 'Tractate on Education ;' (d) Comenius, 'Great

1 The chair at St. Andrew's is held by Prof. J. M. D. Meiklejohn, whose name and work must be well known in the United States.
Didactic.' Each candidate must further give evidence either that he has attended a course of practical instruction in a training-college; or that he possesses the government qualification in the practice of teaching required of graduates and provided in the 'Scottish Code;' or that he has taught publicly for at least one year in a school, and holds such a certificate of practical skill from the head master as may be considered satisfactory by the university. Lastly, each candidate must satisfy the university of his practical aptitude as a teacher in some special subject or subjects in which he has received instruction in the university or in any institution recognized by the university as qualifying for degrees. I may note in conclusion that the fee for the diploma is two guineas. I have not yet been able to ascertain whether St. Andrew's is likely to follow the lead of Edinburgh in instituting a school-masters' diploma.

It only remains for me to speak of the College of Preceptors in London. This institution provides three courses of evening lectures for teachers, and confers diplomas of three grades, - associateship, licentiateship, and fellowship. The lectures are on $(a)$ psychology and its relation to teaching; $(b)$ practical teaching; and $(c)$ the history of education. The courses used to consist of ten lectures each; but in future the number of lectures on the first two subjects will be doubled. They are open free to all members of the college (annual subscription one guinea), or to any one else on payment of half a guinea for each course.

The examinations for the three kinds of diploma all include tests of a general education of gradually increasing severity; but these tests may be omitted in the cases of persons possessing a university degree, or who have passed some examination equally satisfactory to the college. What most concerns us here are the strictly pedagogic subjects. To begin, then, with the associateship. Candidates must give evidence of having been at least one year engaged in teaching, or of having attended a year's course of the lectures for teachers at the college. The subjects are, (I) the elements of mental and moral science; (2) physiology, with special reference to its application to the laws of health and to physical and mental education; and (3) lesson-giving and criticism of methods, including the sketching of a lesson on some assigned subject, the suggesting and discussing of cases of difficulty in teaching and discipline, and the proposing and criticising of methods. For the licentiateship the candidates must give evidence of having been at least two years engaged in teaching. The subjects are the same as for the associateship, with the addition of logic in its application to education; while the third section now includes " a thesis on the life, character, methods, and influence of some distinguished educator to be selected by the candidate, or a description of the organization and methods of some school of repute derived from personal inspection and examination." The candidates for the fellowship must give evidence of having been not less than five years engaged in teaching. Sections No. I and No. 2 are the same as before, but of a more advanced character. Section 3 becomes "government of a school, including lesson-giving and school organization in all its departments." Section 4 is "the history of education and educational methods, with studies of distinguished educators, English and foreign; and a description and discussion of the methods and organization of schools and colleges of note at home and abroad." The fees in the first case, for examination and diplonia together, are two guineas; in the second, three guineas; and in the third, six guineas. Examinations are held twice a year, - at midsummer and Christmas. During 1886 , for the three diplomas together, 136 candidates entered, -70 men and 66 women. Of these, 45 obtained the associateship, 4 the licentiateship, and I the fellowship. This will serve to show both how much the examinations are used, and the severity observed in awarding the diplomas.

I fear that all this will read as a very dry statistical account. It would have been pleasanter and easier to have flowered forth into criticism and exhortation; but those who really wish to kncw how matters now stand, will, I believe, find my facts more useful than my views are ever likely to be. H. Courthope Bowen.

THE total number of children within the age of compulsory school years in Prussia is 5,500,000, of whom 4,800,000 attend school. There are more than 700,000 teachers, in 33,000 elementary schools. The average number of pupils to one teacher is 78 . 